\title{
Políticas de ciudad: planear la ciudad para reivindicar la dimensión humana ${ }^{1}$
}

\author{
Lucas Correa Montoya \\ Universidad de los Andes. Bogotá, Colombia. Email: 1correa@uniandes.edu.co
}

\begin{abstract}
Resumen: Las políticas de la ciudad deben ser entendidas como aquellas que abordan asuntos relacionados con un sector o territorio específico, la ciudad o una parte de ella. Sin embargo, si éstas se entienden dentro del marco del derecho a la ciudad, se convierten en políticas que van más allá de la idea de la ciudad como un problema territorial o funcional. Se convierten entonces, en políticas que atienden una realidad compleja, que abordan factores tanto territoriales y funcionales como éticos y humanos. Las políticas de ciudad entonces, deben apuntar hacia esa realidad de creación humana, que es compleja y que por tanto está siempre en construcción.
\end{abstract}

Palabras claves: Políticas de ciudad, planeación de la ciudad, participación ciudadana, derecho a la ciudad

\section{City policies: planning the city to claim for the human dimension}

\begin{abstract}
City policies must be understood as those that address issues related with a specific area or territory, the city or a part of it. Nevertheless, if these are understood within the frame of having a right to the city, they become policies that go beyond the idea of the city as a functional or territorial problem. They, hence, become policies that serve a complex reality, that adress territorial and functional as well as ethical and human issues. Therefore, city policies must point out towards this human creation reality, which is complex and is thus always in construction.
\end{abstract}

Keywords: City policies, city planning, citizen participation, right to the city

\section{Políticas da cidade. planejamento da cidade para recuperar a dimensão humana}

Resumo: As políticas da cidade devem ser entendidas como aquelas que tratam de questões relacionadas a um setor específico ou território, cidade ou uma parte dela. No entanto, se estes são entendidos no âmbito do direito à cidade, tornam-se políticas que vão além da idéia da cidade como um problema territorial ou funcional. Tornam-se, em políticas que visem uma realidade complexa, que tratam tanto os fatores territoriais e funcionais, como éticos e humanos. A política da cidade, então, deve enfrentar a realidade da criação humana, que é complexa e, portanto, está sempre em construção.

Palavras-chave: políticas da cidade, planejamento urbano, participação cidadã, direito à cidade

$$
* * *
$$

\section{Palabras Iniciales}

La garantía del derecho a la ciudad tiene una estrecha relación con la acción pública sobre la ciudad, buena parte de sus contenidos normativos dependen de ella para su realización. El presente artículo parte de una situación poco reconocida y abordada actualmente: las políticas de ciudad más allá de las políticas urbanas o sectoriales en la ciudad.

Sobre la base de entender la ciudad desde lo humano y lo político, no desde las estructuras, la forma y las funciones, el texto realiza un abordaje teórico sobre las políticas de ciudad, lo que ellas deben ser, permitir y potenciar en la ciudad. Lo anterior con el objetivo de aportar en el reto de la transformación de la acción pública para reivindicar la dimensión humana, la participación y la ciudadanía en el quehacer de la planeación de la ciudad.

Difícilmente se ofrece a un debate concluido o una receta de elementos prácticos que deben desarrollarse. Por el contrario, se presentan reflexiones orientadas a analizar y diseñar políticas de ciudad potenciadoras del derecho a la ciudad desde su faceta de la participación ciudadana. 


\section{Políticas de ciudad: la ciudad y a la que se refieren y propuesta de concepto}

Las políticas de ciudad son políticas públicas ${ }^{2}$ que entienden la ciudad como una realidad compleja. La discusión sobre las políticas de ciudad no se enmarca únicamente en su entendimiento como policy, es decir, desde la acción pública, sino que implican una serie de vínculos e interrelaciones con la política como juego del poder, como politics, y sobre la manera cómo este juego impacta la acción y cómo esa misma acción pública da cuenta de ese juego diverso y complejo que se da en un lugar: la ciudad.

Desde estos planteamientos las políticas de ciudad pueden abordar cualquier asunto o sector concreto, más o menos de índole territorial, pero en todos los casos, teniendo como norte el derecho a la ciudad, deberán fomentar o potenciar una idea de ciudad específica: la idea que la ciudad no es un problema únicamente territorial o funcional, sino que ella es una realidad compleja, una creación humana, éticamente comprometida, una realidad que integra valores, un proyecto colectivo que busca continuas y nuevas significaciones, así como su trascendencia. Una creación humana que es tensa, contradictoria y discontinua, siempre inacabada, siempre en construcción, generadora de una gran frustración y de un universo de posibilidades.

Las políticas de ciudad se preguntan cómo desde el conflicto, el juego y la arena política (politics) hacía la acción pública en clave de derecho a la ciudad (policy) tiene lugar y se posibilita efectivamente el tipo de ciudad planteada. Para ello se presentan una serie de cuestiones concretas a las que las políticas de ciudad deben atender, la forma como específicamente se aborde puede depender, en el marco de la participación, de las diversas elecciones que se den a través de la acción pública.

El primero de dichos criterios es entender y abordar a los hombres y las mujeres como elemento primigenio y transversal de las políticas de ciudad, de la acción pública. La ciudad es, con García Moreno (1996: 175), la concreción de la experiencia de ser humano, del habitar, del poetizar. Ella implica un reto en relación con el sujeto, un reto individual y colectivo, un desafío de su comportamiento en la comunidad, un problema ético.

Los hombres y las mujeres no pueden ser abordados tangencialmente o ignorados por las políticas de ciudad. Las soluciones típicamente modernas, racionales y funcionales que pretenden un entendimiento de la ciudad desde las geometrías, las infraestructuras, los usos, los flujos, las funciones, para dar orden al supuesto caos urbano, generalmente atienden a las necesidades de la ciudad consideradas en abstracto, los hombres y las mujeres se enumeran y clasifican en estratos socio-económicos a partir de su ubicación en el sistema de producción, de acuerdo con su ingreso, con el lugar que ocupan, pero no se les ve como sujetos provistos de deseo, que generan la historia y sus transformaciones, que tejen horizontes de futuro y se relacionan entre sí; que crean la ciudad (García Moreno, 2003: 195).

Las políticas de ciudad no se agotan reconociendo la simple presencia de hombres y mujeres, la segunda cuestión implica que éstas generen, permitan y fomenten el encuentro, el intercambio, la posibilidad de construcción colectiva y plural por parte de todos y cada uno de esos sujetos. Desde la herencia griega, el demos fue una de las instituciones de la humanidad en donde el reconocimiento y aceptación del otro diferente ${ }^{3}$ permitió la creación de la ciudad y la constitución del ciudadano, de otro lado la polis constituyó tanto el espacio físico, basado en el ágora, de carácter público y colectivo (espacio público-público) ${ }^{4}$ donde los seres humanos permanecen mucho tiempo, intercambian muchas cosas y crean nuevas significaciones (Malaver, 1996: 245), posibilitar el encuentro con el otro, de los hombres y las mujeres en y por la ciudad es el norte que deben perseguir las prácticas de gobierno, las políticas de ciudad y la acción ciudadana.

No basta un sujeto que deambule en su interior, se requiere que éste sea consciente de sí, tenga su propio proyecto de vida en ella y que haga parte de un colectivo; esa necesidad debe ser potenciada asertivamente por las políticas de ciudad. Para la ciudad entendida más allá de lo urbano, de lo físico, entendida como creación humana, no bastan los hombres y las mujeres como receptores, es necesario que ellos se hagan y que ella permita sujetos actores, sujetos activos en y por la ciudad, los hombres y las mujeres deben transformarse en ciudadanos y ciudadanas. "Una ciudad sin ciudadanos es solo un espacio urbano en donde habitan personas" (Malaver, 1996: 246). 
Somos los ciudadanos y ciudadanas quienes con nuestros comportamientos producimos la ciudad y los elementos que en determinadas circunstancias la hacen digna, liberadora, disfrutable. Dado que ni la sociedad ni la ciudad son evidentes o unívocas, sino complejas y diversas, la pretensión de refundarla o fijar los parámetros para un proyecto colectivo requiere de un proceso de construcción grupal, comunitario y crítico para establecer los marcos de relación de la ciudadanía y el poder, así como su organización y distribución. Bajo este criterio las políticas de ciudad se presentan como un proceso que como lo establece Viviescas (2002: 53-57), requiere de una apuesta político-cultural integrada por lo menos de: (a) la identificación del otro, de la diferencia como parte fundamental de la construcción de la sociedad civil en la construcción de la participación; (b) el reconocimiento de la complejidad de la sociedad y de su construcción, las cuales además de ser un reto del pensamiento, debe fundarse en el encuentro y reconocimiento del otro por medio de la discusión, el intercambio, del despliegue de la libertad de pensamiento y acción.

De esta manera las políticas de ciudad implican un reto ético, un desafío relativo a la forma como los ciudadanos y las ciudadanas se comportan en la ciudad, como reconocen y aportan a la diferencia, a la construcción colectiva, plural y múltiple. Reto que se manifiesta en crear lugares de vivienda y trabajo, planear el crecimiento de las ciudades para que estos nuevos pobladores tengan experiencias significantes; que las ciudades no sean un factor de exclusión y segregación socio-espacial, que crezcan las posibilidades de encuentro, de tener un derecho al lugar, a que éste sea bello y significante, a tener derecho a la ciudad (Borja, 2005); reto que además no debe ser únicamente satisfecho desde quienes la gobiernan, planean o gestionan, sino también desde la acción de sus ciudadanos en todas sus manifestaciones.

Las políticas de ciudad y el desarrollo de los criterios generales planteados se logran, entre otros, mediante la construcción de decisiones públicas, de políticas concretas, sean estos planes, instrumentos y proyectos, de forma participativa. De esa manera no sólo se incluye la dimensión humana de forma vertical, sino se la integra de forma horizontal, permitiendo su encuentro, su reconocimiento, su valoración positiva y su redefinición ética.

\section{Las políticas de ciudad: implicación y trascendencia de las políticas urbanas}

La idea de políticas de ciudad que se ofrece, que deriva del concepto de derecho a la ciudad, es una invitación a entender que gobernar, planificar y gestionar la ciudad va más allá de enfocarse en lo urbano, en las funciones (Le Corbusier, 1973), se trata de abordar con la acción pública, desde el gobierno, la planificación y la gestión, la complejidad y diversidad de la ciudad.

En la ciudad, con Rossi (1986: 77), no sólo resulta importante lo que es apreciable por la vista, lo que puede concretarse ante el sujeto, la calle, la plaza, allí se materializa la estructura urbana, pero la ciudad, como vida y alma, va más allá de la forma, de la dimensión física, la cual si bien materializa su existencia, no la define. La ciudad, más que un agregado hombres y mujeres, de elementos construidos, implica una posibilidad distinta a la mera suma de sus partes, la posibilidad de un entendimiento político, de la construcción de una comunidad y de un proyecto de vida colectivo. La urbanización no es ciudad automáticamente, en muchos casos constituye negación de ella misma. Lo urbano es un insumo de ciudad que hay que materializar a través de ejercicio de la democracia, la política, la participación y la ciudadanía (Borja, 2005: 30).

La principal atención por la dimensión física en los estudios y las políticas urbanas no es un fenómeno aislado, sino una condición crónica de la modernidad, la cual en palabras de Berman (1989) hace parte de la excesiva confianza que ésta ha puesto en la racionalidad, en "los sólidos" y en los relatos liberadores y emancipadores (Lash, 1997) típicamente de tendencias racionalizantes y normalizadoras.

Los sentidos aplicados a la ciudad ponen en crisis la construcción urbana de la modernidad, caracterizada por prescindir de las sensaciones y las percepciones y pretender la construcción de formas y experiencias urbanas sensorialmente neutras, "sólidas" en las palabras de Berman (1989). Sobre la base de lo expuesto la ciudad, y en extensión su gobierno y planeación, también se integra por las formas como ella es percibida y sentida por sus habitantes (García Vázquez, 2004: 137). 
Esta condición no es por nada un obstáculo, sino el elemento germinante de las posibilidades de ciudad y de las políticas que a ella se refieren, es la capacidad de sentirse en frustración lo que permite a los hombres y las mujeres ser actores de su propio destino, del destino comunitario y de aquel de la ciudad, es de esa frustración y condición de inacabada de la ciudad y de la condición humana que surgen las posibilidades de pensar y gestionar los proyectos de vida individuales y colectivos.

La multiculturalidad entendida como la enorme colección de subjetividades que tienen lugar en la ciudad, es vista como una cuestión problemática desde los pensamientos más posicionados en el urbanismo actual, de la ciudad moderna. La diferencia y heterogeneidad en la ciudad causan miedos, hostilidad, distancias, una ciudad multicultural, se afirma con Amendola (2000), es conflictiva. La clave para superar el miedo e incorporar en los estudios sobre la ciudad los elementos objetivos y subjetivos está en lograr perder el miedo al conflicto, a la diferencia, olvidar la obsesión a tener experiencias urbanas controladas, purificadas, seguras y homogéneas (García Vázquez, 2004: 77).

Desde las políticas de ciudad como implicación y trascendencia de las políticas urbanas las autoridades y los ciudadanos tienen la responsabilidad de trascender el patrón de una ciudad entendida como un espacio para la vivienda y para el ejercicio de algunas funciones, una ciudad al servicio de la producción, de la competitividad. La atención sobres estos elementos debe nutrirse de acciones que fomenten el encuentro entre las personas, el intercambio y la producción de la cultura, el desarrollo de sus proyectos de vida y más aún la participación directa en el proyecto de ciudad, proyecto que no debe ser dado de forma vertical por la vía tecnócrata, sino construida horizontalmente a partir de la reflexión.

Es necesario comprender, como la plantea Giraldo Isaza (2001: 9), las diferencias entre los elementos físicos y políticos de la ciudad. Los primeros caracterizan nuestra necesidad de asentamiento, de abandonar la vida nómada hacia la vida sedentaria producto de la revolución agrícola, la cual dio origen a las agrupaciones poblacionales reunidas en un mismo lugar sin la existencia de la democracia ni de la filosofía política que son la base de la creación de la polis. Ella, si bien se levanta sobre la realidad construida requiere de la creación de nuevas instituciones como la ciudadanía, de donde surge un ser distinto, un ser creador de leyes y cuestionador de lo establecido. La ciudad es imposible sin la existencia real de la democracia política, sin la creación de la ciudadanía, sin el segundo tipo de elementos, aquellos políticos.

Como implicación y trascendencia de las políticas urbanas, y en línea con los planteamientos expuestos, la idea de políticas de ciudad que en este texto se plantea, entiende el espacio en los términos de Lefebvre (1991) como un producto espacial y social que opera en tres niveles, los cuales no necesariamente se presentan de forma separada. En el primer nivel se entiende que la producción del espacio surge como efectos de las prácticas espaciales, basada en las relaciones y locaciones de producción y reproducción por parte de los actores sociales.

En el segundo nivel se piensa la producción del espacio en términos de "representación del espacio" que se refiere a concepciones y diseños formales que se relacionan directamente con el orden gubernamental, arquitectónico o científico del espacio. Entender la producción del espacio bajo este enfoque se basa en esquemas de poder de acuerdo a los cuales se racionalizan los espacios de la ciudad y normalizan las conductas de los hombres y las mujeres en él. Corresponde a la típica tendencia moderna y funcionalista.

Finalmente en el tercer nivel, la producción del espacio se refiere a los "espacios representacionales", éstos son manifestaciones de la imaginación, la personificación y el deseo, están atados a prácticas simbólicas y artísticas, diseños subversivos y clandestinos, experiencias libres o dominadas. Este nivel refiere al espacio como es vivido directamente, a través de los símbolos y las representaciones de los hombres y las mujeres.

Esta tipología trata al espacio como una producción desde la práctica, las percepciones y la imaginación, de manera que los mismos espacios pueden ser reproducidos, representados y experimentados de diferentes formas. Tonkiss (2005: 3) argumenta que los espacios producidos están nutridos por la acción del pensamiento, sugiere que la forma urbana no está hecha sólo de materiales y de cosas, sino también de sentimientos, significados, lenguaje y símbolos y que estos también deben ser parte integral de su gobierno, planificación y gestión. Dar una respuesta desde lo público y lo ciudadano es el reto primordial de las políticas de ciudad y constituye, además, el principal rasgo que las diferencia de las políticas urbanas. 


\section{Las políticas de ciudad y su reto político}

En la ciudad, el poder se hace visible, construirla no resulta únicamente una cuestión financiera, ni de arquitectura o de ingeniería. Hacer ciudad y políticas sobre ella es actuar para crear el marco en que desarrolla la vida de las personas, se ordenan los elementos físicos y se permiten las dinámicas y prácticas sociales, hacer ciudad es ante todo una cuestión política (Borja, 2005: 95 y 120), una cuestión sobre la forma en que se otorga, ejerce, distribuye y controla el poder, mecanismo para organizar las vidas individuales y construir los proyectos colectivos, por ello; como construcción humana la ciudad, y las políticas sobre ella implican, además de un reto humano y ético, un reto político desde la teoría hasta la acción.

En la ciudad de la periferia global la mezcla de la tradición, la modernidad y la posmodernidad, ha generado diferentes preguntas y problemas que deben encontrar respuestas desde su gobierno, planeación y gestión: cómo resolver preocupaciones que van desde el control espacial y morfológico, hasta cuestionamientos sobre el cómo hacer para que la ciudad permita el desarrollo de las redes que resultan de las relaciones intersubjetivas, en el marco de una ética que defienda y valore el desarrollo particular de los ciudadanos, enmarcada en un campo simbólico que permita que dichas redes, con todos los imaginarios que las acompañan, con las particularidades del goce que cada quien introduce, puedan moldearse y permitirle a cada sujeto expresar su deseo (García Moreno, 2003: 197).

Finalidad que integra necesariamente un reto ético con dos implicaciones principales: de un lado el reto ético de la ciudad moderna no significa recuperar la idea nostálgica de polis griega $^{5}$, sino a responder a las necesidades sociales y materiales impostergables, además de todo funcionalismo moderno ella debe facilitar el encuentro, la solidaridad, la cooperación y la convivencia entre hombres y mujeres; de otro lado dicho encuentro debe permitir la cualificación de los sujetos, no se trata solamente de contar con hombres y mujeres dignos, conscientes de sí mismos, protagonistas de sus proyectos de vida, sino que estos adquieran la calidad de ciudadanos, que sean parte, adicionalmente, de un proyecto colectivo, titulares de derechos y obligaciones como pertenecientes a la ciudad, que tales ejerzan y gocen plenamente del derecho a la ciudad.

Derivado del reto político, las políticas de ciudad deben buscar empoderar a la comunidad ciudadana, organizarla y proveerla de medios eficaces para participar y decidir sobre la ciudad que acoge sus vidas y proyectos. Se trata de ir más allá de lo urbano, de disponer un orden para los elementos construidos y refundar políticamente la ciudad, las políticas, y las prácticas de planeación.

Recogiendo los criterios planteados, no basta el abordaje de la urbanización, las políticas de ciudad deben permitir el encuentro o el reconocimiento del otro, social y colectivamente, de lo contrario lo urbano no tiene razón de ser y la reflexión y posibilidades políticas no tienen lugar. La ciudad y las políticas sobre ella deben cumplir su función de socialización y construcción comunitaria, solo así se permite entenderla como construcción política, comunitaria, democrática y participativa.

El reto político de la ciudad conlleva una serie de implicaciones que ayudan a definir cuáles son los elementos que en ella se debe permitir y hacia los cuales deben enfocarse las políticas de ciudad sin importar las temáticas o asuntos que se aborden: en primer lugar implica un desafío político, es decir, se da en su interior una lucha por el poder, por cómo éste se adquiere, se distribuye, se ejerce y se controla; en segundo lugar se presenta la necesidad de fomentar y fortalecer la comunidad ciudadana, en tercer lugar se encuentra una necesidad de prácticas democráticas directas; en cuarto lugar supone el reto de fomentar la participación ciudadana; y en quinto lugar requiere de la presencia y fomento de un tipo de sujeto en y por la ciudad, el ciudadano. Cada una de estas implicaciones se abordarán en apartados separados.

\section{Las políticas de ciudad: la acción pública como desafío relativo al poder}

La política ${ }^{6}$ se refiere a la "forma colectiva de definir el destino de todos y todas" (Velásquez Carrillo, 2003: 19), a las prácticas y estudios sobre el poder, sean estas públicas o privadas, se ocupa de la forma como 
éste se obtiene, distribuye, ejerce y controla. La política en relación con la ciudad presenta varias características, de acuerdo con Rossi (1986: 273) es preeminente, decisiva, propia y constitutiva.

El desafío relativo al poder que implican las políticas ${ }^{7}$ de ciudad como acción estatal se da en un punto medio entre la política entendida como politics y como policy y se orienta a responder al cuestionamiento de cómo la acción pública debe dar cuenta de la diversidad y amplitud de los reclamos, actores y juegos políticos que la ciudad permite. Así, la ciudad es un problema humano, democrático y de ejercicio de la ciudadanía, un desafío de cómo se obtiene, maneja, ejerce y controla el poder (Viviescas, 2000), y por tanto a este asunto deben referirse las políticas de ciudad desde la acción pública.

La ciudad se encuentra en una constante tensión ente lo particular y lo universal, entre lo individual y lo colectivo, entre lo público y lo privado, dicha naturaleza dicotómica da lugar a los distintos intereses, propósitos, ideas y valores que están en juego, que dan contenido al desafío relativo al poder que se materializa en la acción pública.

El desafío del poder en la ciudad se refiere a un problema de elección por la ciudad que se realiza, por las ideas de ciudad que se llevan a cabo, no sólo los resultados, sino también los medios a través de los cuales se llega a ellos. La ciudad está plagada de ideas e imaginarios sobre ella, de realidades, de utopías, en la construcción de la ciudad hay un proceso de influencias, intercambios y contraposiciones entre los hechos urbanos, tal y como se procesan en la realidad y las propuestas ideales de las que surgen (Rossi, 1986: 64).

Los ciudadanos y sus organizaciones en la ciudad quieren diferentes cosas, defienden determinadas acciones, valores e intereses; al mismo tiempo tienen diferentes visiones de lo que una buena ciudad es, y más importante aún, lo que ésta debería ser. Como desafío del poder, las políticas de ciudad deben permitir esa diversidad de reclamos sociales, culturales, económicos, la competencia por estos reclamos y la forma como se manifiestan en el poder y en el espacio integran la idea política de la ciudad, como espacio y lugar para y por la deliberación pública, política, democrática y participativa. Las políticas de ciudad deben poder permitirle a los ciudadanos participar en la idea de futuro colectivo que mediante la acción pública y privada se construye.

Como lugares donde las cuestiones sociales toman formas espaciales, las ciudades son contextos críticos para preguntarse y pensar las cuestiones del poder. Adicionalmente son un interesante lugar para el desarrollo de movimientos sociales, proveen recursos espaciales y sociales para la movilización y acción política en la medida que proveen: (a) el espacio público en sí mismo, calles, parques y plazas; (b) información y redes sociales que favorecen la movilización; y (c) las condiciones para las expresiones colectivas de reunión, asociación y manifestación (Tonkiss, 2005: 65).

En síntesis la relación de la lucha por el poder y la ciudad puede entenderse desde varias posiciones, la primera de ellas es considerar a los movimientos sociales como agentes en la ciudad, teniendo como objetivo político el espacio y, en segundo lugar usando dicho espacio como fuente para la movilización política. El espacio público, la calle, el transporte, entre otros, se constituyen en lugares para la micro-política en donde los individuos ejercen, en mayor o menos escala sus derechos y en concreto su derecho a la ciudad (Tonkiss, 2005: 59).

Sea cual sea la temática, las políticas de ciudad, como materialización del derecho a la ciudad en la acción pública, deben responder al desafío del poder que implican, permitiendo el encuentro y la construcción colectiva lo más horizontal y democrática posible.

\section{Políticas de ciudad: oportunidad para fomentar y fortalecer la comunidad ciudadana}

La contienda por el poder que tiene lugar en la ciudad y la necesidad que esta se plasme, en su diversidad, amplitud y complejidad, en la acción pública, en las políticas, no sólo tiene lugar en la ciudad como espacio, sino que tiene como actor principal a la comunidad que en ella debe anidarse: la comunidad ciudadana. 
Es necesario afirmar que la ciudad continúa siendo el lugar primario de la comunidad ciudadana. Tal idea no pasa inadvertida, Tonkiss (2005: 9), Bauman (2010) y otros autores consideran que la ciudad moderna ha desconfigurado, por efectos de su normalización y racionalidad cualquier posibilidad de comunidad, es más, ella es considerada un fenómeno premoderno y por tanto negación de lo urbano: "la comunidad debe ser vista más como un elemento de fantasía política o de sociología romántica, más que como una realidad social", plantean.

Pero si bien la indiferencia, la privacidad, la soledad y el anonimato que caracterizan la ciudad latinoamericana entre la tradición, la modernidad y la posmodernidad; son los indicadores de alienación de lo humano en la ciudad, de la negación de la comunidad ciudadana, ellos mismos amplían el espectro de libertad que la ciudad permite y son la base para la recuperación de tal idea.

Ese insumo de comunidad para la construcción política de la ciudad, desde el desafío del poder y desde la acción pública, es retomada por Tönnies (2002), para lo cual aborda las diferencias y tensiones entre los conceptos de comunidad ${ }^{8}$ y sociedad o asociación ${ }^{9}$.

La primera de ellas se refiere a un modo de interacción donde los lazos sociales están basados en la mutua dependencia y donde las relaciones de los individuos con los demás tienen lugar y derivan sus significados de un grupo más grande. La comunidad, de acuerdo con esta definición se materializa en la familia y en las amistades o desde las palabras de Gorz (2002), se conforma por la entrega de cada uno de sus individuos, en la cual confluye su cooperación, afectos y conflictos, los cuales la consideran suya por efectos de la cohesión que genera.

En segundo lugar la sociedad o la asociación, define un modo de interacción que tiende a lo impersonal, instrumental y voluntario. En ella se envuelven relaciones e interacciones sociales basadas en intereses racionales en lugar que en sentimientos de pertenencia, y toman forma a partir de normas externas y formales; o desde las ideas de Gorz (2002: 198) como un sistema de relaciones dirigidas por una organización institucional, infraestructuras de comunicación y producción; la sociedad es externa a sus miembros, no es el resultado de la colaboración voluntaria.

La comunidad ciudadana a partir de los planteamientos de Tönnies y Gorz debe entonces estructurarse como una mezcla de las ideas de sociedad y comunidad. Una figura unida por la voluntad, los afectos y los intereses de sus miembros, sobre la base de reglas claras, espacios institucionalizados, mandatos y objetivos concretos. De esta diferenciación surge el reto de la ciudad en la periferia global en relación con la comunidad ciudadana, ¿cómo construir un grupo de base, como la sociedad o asociación que, a partir de las relaciones sociales fundadas en la racionalidad y en la impersonalidad, esencialmente formas modernas y urbanas de sociabilidad, permitan disponer de una plataforma comunitaria para que el desarrollo político de la ciudad pueda tener lugar, es decir, una figura intermedia entre la comunidad y la sociedad?

Esto necesariamente lleva a asumir el reto de superar la paradoja identificada por Tonkiss (2005: 13) según la cual las ciudades, en función de su densidad, tamaño y heterogeneidad producen diferentes tipos de interacción y de experiencias subjetivas, integran una tensión entre la proximidad física y las distancias sociales. Ciudades que generan la proliferación de los encuentros junto con el debilitamiento de los vínculos sociales, muchas personas comparten la vida en común, los lugares, las oportunidades, pero entre ellas se encuentran numerosas desigualdades y profundos abismos que las separan socialmente.

Las políticas de ciudad como principal forma de desarrollo del derecho a ésta deben fomentar la conformación y el fortalecimiento de la comunidad ciudadana, grupo necesario para garantizar la participación ciudadana e implementar prácticas de planeación de la ciudad horizontales y cercanas a los hombres y a las mujeres, a sus intereses y deseos.

\section{Políticas de ciudad: la necesidad de prácticas democráticas directas}

La tercera implicación a la cual deben dar respuesta las políticas de ciudad es tener claro que el entendimiento político de la misma integra la necesidad de prácticas democráticas directas y la actuación clara 
y decidida para fomentarlas y conseguirlas. Esta necesidad parte de la idea que entre la ciudad y la democracia media una relación de causa-efecto. De un lado la ciudad es un lugar e institución que puede potenciar fuertemente la democracia; la proximidad ciudadana, los encuentros, relaciones y vínculos que en ella tienen lugar son insumos propios de ésta. Pero de otro lado, ella no es solo causa de la democracia, al mismo tiempo la ciudad se define por las prácticas democráticas que en ella tienen lugar, sea con mayor o menor intensidad, pero en todo caso no puede considerarse como ciudad una construcción social de y para la dominación y la represión. Sólo en el marco de la libertad, la igualdad, la representación y el control del poder puede erigirse una ciudad.

La posmodernidad aplicada a la ciudad, en los términos de Amendola (2000) y Lyotard (2004), implica la generalización de la desconfianza en los metarrelatos que caracterizaban a la modernidad, la totalidad, la normalización, la emancipación y la racionalidad son puestas en duda y la cotidianidad es permeada por lo contingente, lo fragmentario, lo relativo y lo temporal. La ciudad es el lugar de tales características, diversidad, pluralidad, diferencia y liquidez son los elementos que deben potencializarse por medio de las prácticas democráticas directas para y en las políticas de ciudad.

Amendola (2000: 73) lo explica de forma sencilla: la ciudad es un collage en donde las diferencias no constituyen ya una excepción que hay que normalizar, sino experiencias distintas que hay que tejer, diversidad que hay que ensamblar. La ciudad genera la posibilidad de encuentro desde las diferencias, pero, una vez ha fracasado el proyecto moderno totalizador y homogenizante, todos los sujetos son echados a su suerte en la ciudad, en su cotidianidad; el reto de construir políticamente la ciudad está a la orden del día.

La necesidad de prácticas democráticas directas, desde una aproximación ideal se refiere a otorgar un poder real de la comunidad, se basa en la posibilidad efectiva de los individuos de tomar parte de las decisiones de los asuntos más relevantes de su vida comunitaria. Las prácticas democráticas que implica el entendimiento político de la ciudad requieren de procesos de armonización entre manifestaciones representativas (indirectas) y participativas (directas) que prefieran éstas últimas (Höffe, 2004: 101).

Las prácticas democráticas indirectas, en los términos de Höffe (2004: 110-112), se presentan como poco apropiadas para la satisfacción de las necesidades de ciudad, políticamente entendida, en la medida que: (a) no responden a las configuraciones territoriales modernas, caracterizadas por grandes extensiones territoriales y demográficas; (b) implican un premio a la demagogia, privilegian los acontecimientos fortuitos y reducen la responsabilidad y racionalidad de la decisión política; y, entre otras, (c) prescinden de los ciudadanos para la decisión de temas de alta complejidad.

De otro lado, las prácticas democráticas directas, que constituyen el imperativo del entendimiento político de la ciudad, no excluyen a las indirectas sino que las amplían y consisten en el poder de la comunidad para decidir, no sólo en materia de personas, candidatos y representantes, sino también sobre asuntos específicos, de políticas de ciudad.

Este tipo de prácticas deben preferirse en la ciudad en la medida que: (a) implican un fortalecimiento práctico de la soberanía popular, por sus efectos la "democracia de espectadores" se transforma en una "democracia de cooperación"; (b) aumentan la legitimidad e identificación ciudadana con la acción política; (c) extienden la eficacia de las decisiones políticas y el compromiso comunitario; (d) permiten poner freno al poder desbordante de las clases políticas tradicionales y disminuyen la distancia social entre gobernantes y gobernados; y finalmente, (e) estimulan la educación para la madurez política (Höffe, 2004: 109).

De esta manera, un gobierno y políticas de ciudad que fomenten prácticas democráticas directas requieren de un ambicioso proyecto de innovación política, que en los términos de Borja (2005: 275) implica por lo menos: descentralizar y localizar las funciones públicas y políticas en localidades y barrios, en la medida que estas prácticas requieren de decisiones más próximas en donde haya una participación más cercana de la sociedad civil sin privatizar este ámbito de decisión; y mejorar el flujo y el acceso a la información y la multiplicación de la participación de todos los colectivos sociales, todo ello mediante los procesos participativos reales y efectivos. Se trata que la política en la ciudad (politics) se permee de prácticas democráticas directas que den lugar a acciones públicas, políticas de ciudad (policy) fomentando así el círculo virtuoso de la democracia participativa. 


\section{Políticas de ciudad: el reto de la participación ciudadana}

Como desafío relativo al poder e imperativo democrático, el entendimiento político de la ciudad presenta una cuarta implicación a las políticas públicas, el reto de fomentar, permitir y usar la participación ciudadana como elemento trasversal en la discusión, decisión e implementación de los asuntos y de las políticas que le son relevantes, implicación que además constituye la segunda faceta del derecho a la ciudad. La participación ciudadana no es una exigencia retórica, ni una formalidad informativa, sino la posibilidad real de un debate político y cultural en el que han de poder intervenir, en igualdad de condiciones y efectivamente, múltiples actores sociales (Borja, 2005: 183).

El desarrollo de procesos participativos de planeación de la ciudad que tengan en cuenta la dimensión humana debe también incluir, de acuerdo con Amendola (2000: 93) las necesidades y los deseos de los distintos grupos sociales, conciliarlos y valorarlos con igual peso y dignidad en sus posibilidades de reflexionar, orientar y actuar sobre la ciudad.

La necesidad de fomentar la participación ciudadana, de articular la representación local, del consenso y de la solidaridad de la comunidad ciudadana son centrales para revertir el patrón político que, según Borja (2005: 91-92) ha caracterizado el gobierno y la planeación de la ciudad y en el que la participación: (a) es un quehacer político que se limita al mero flujo de información; (b) es efímera y excepcional; y (c) se entiende como una servidumbre molesta que retrasa los procesos técnicos y burocráticos de toma e implementación de decisiones.

Dicho reto implica sobrepasar algunos obstáculos frecuentes a los que se enfrenta la participación como consecuencia del entendimiento político de la ciudad, algunos de estos son: (a) la desconfianza en los políticos tradicionales; (b) el elitismo tecnocrático de los profesionales al servicio de la ciudad; y (c) la demagogia y politización de las entidades vecinales.

Para ello, junto con Borja (2005: 92), se hace necesario reforzar la atención en que: (a) el proceso de construcción de la ciudad no sea tomado por élites, para ello es necesario involucrar a todos los actores sociales interesados en una determinada cuestión; y (b) la participación es una alternativa dirigida a crear soluciones que respondan a la multiplicidad de los retos e intereses de una sociedad diversa y por tanto, pese a sus limitaciones, debe ser reconocida como un mecanismo promisorio.

Mecanismo que resulta aún más promisorio en el barrio, en lo local. Los ciudadanos se relacionan cada vez más con los otros en múltiples escalas, y esta diversidad tiende a desdibujar la importancia que alguna vez tuviera el barrio, la cual no puede dejarse atrás, porque pese a las relaciones globales y virtuales crecientes, en él, anida aún la vida cotidiana; el reto de la participación implica la necesidad de fomentar su importancia política, las dinámicas de descentralización municipal y de participación ciudadana en los ámbitos locales, tema en torno al cual gira el problema de esta investigación (Borja, 2005: 53-54). La reconstrucción de la importancia política del barrio en presencia de unidades urbanas cada vez más grandes, macro, complejas, diversa en extensión, población, función y diversidad. En presencia de metrópolis y megalópolis, el barrio adquiere la importancia de ciudad o microciudad en la ciudad.

\section{Políticas de ciudad: estrategia para potencia el pleno ejercicio de la ciudadanía}

La ciudad, si bien se levanta sobre la realidad urbana requiere de la creación de nuevas instituciones como la ciudadanía, de donde surge un ser distinto, un ser creador de leyes y cuestionador de lo establecido. La ciudad es imposible sin la existencia real de la democracia política, sin la creación de la ciudadanía (Giraldo Isaza, 2001: 9).

El ciudadano se perfila como el representante por excelencia del tipo ideal de sujeto socializado y responsable, es el habitante de la ciudad, el portador de la cultura cívica quien materializa lo que la ciudad es y posibilita. El ciudadano comparte valores, establece nuevos y actúa según pautas o normas que hacen 
posible la convivencia con la multitud en la cotidianidad (Borja, 2005: 204), potencia la creación de ciudadanos plenos resulta entonces la última implicación de la acción pública a través de las políticas de ciudad.

Un concepto pleno de ciudadanía integra un estatus legal (un conjunto de derechos de los que se es titular), un estatus moral (un conjunto de responsabilidades) y también una identidad por la que una persona se sabe y se siente perteneciente a una comunidad (Cortina: 1998).

Si bien desde el principio la ciudadanía ha ido de la mano con la nacionalidad y se ha visto atada a la idea del Estado-nación, el ejercicio de la democracia representativa liberal y su tránsito hacia la democracia participativa han marcado la senda de la independencia y su reivindicación en y por la ciudad (Borja, 2005: 282-284). En este orden de ideas la ciudadanía se entiende como un vínculo de pertenencia a la ciudad, constituye un estatus o reconocimiento social y jurídico por cual una persona tiene derechos y deberes por su pertenencia a la comunidad ciudadana, casi siempre de base territorial y cultural, sobre la cual se perfila la ciudad políticamente entendida, la ciudadanía supone igualdad, no homogeneidad. Como manifestación política la ciudad implica el elemento fundamental del reconocimiento y convivencia con el otro, elemento que debe permitirse desde las políticas de ciudad como acción pública.

La ciudadanía se origina en la ciudad, ella es intercambio, comercio, cultura, concentración de personas, de edificios y actividades, es el lugar del civismo, donde se da y reconoce la cohesión y la exclusión. En la ciudad, políticamente entendida, los ciudadanos deben realizarse como tales por medio de su participación en los asuntos colectivos, públicos y políticos, deben pasar como lo estable Bauman (2010) de ciudadanos de iure a ciudadanos de facto. De esta manera la ciudadanía constituye un proceso permanente de conquista de derechos formales y de exigencia de políticas públicas para hacerlos efectivos. Los derechos que configuran la ciudadanía son ahora mucho más complejos, la globalización demanda establecer cartas de derechos y fomentar la participación internacional, implica también reinventar la participación local para dar respuesta a la dialéctica local-global, reinventando el ámbito regional, metropolitano y municipal.

La condición de ciudadano representa, en palabras de Borja (2005: 280), un triple desafío para la ciudad, para las políticas sobre ella y para el gobierno local: (a) un desafío político: el estatus jurídico-político que implica la ciudadanía requiere la posibilidad de acceder a él, y usarlo para fomentar el ejercicio y protección de los derechos y las obligaciones ciudadanas; (b) un desafío social: que exige promover políticas que impidan la discriminación y la reducción del ejercicio de la ciudadanía; y (c) un desafío urbano: que requiere hacer que la ciudad, de sus funciones, lugares y monumentos contribuyan a dar sentido a la vida cotidiana de la ciudadanía.

El desafío que presenta la ciudad hoy y las políticas sobre ella, en sus miradas local, central, regional y global es intelectual y político en conjunto con los retos arquitectónicos, económicos o administrativos, es un desafío de valores, no solamente un problema funcional que se resuelva por la vía tecnócrata.

La ciudad es causa y consecuencia del ejercicio pleno, serio, activo y consciente de la ciudadanía y a su vez ésta tiene como lugar por excelencia a la ciudad, como se planteó, esta relación de causa-efecto conlleva necesariamente a lo que Fernandes (2006b) ha denominado la redefinición del hombre desde la ciudad. Parafraseando el pensamiento de Lefebvre, argumenta que más ahora que nunca en la historia de la humanidad, los hombres y las mujeres contemporáneos son la síntesis de su vida social, familiar y profesional, y las diferencias individuales no pueden seguir siendo ignoradas. Los ciudadanos contemporáneos, indica, no pueden seguir siendo definidos por su nombre, apellido o por su lugar de residencia. En cambio deben definirse por la forma en que pertenecen a una red de distintas prácticas sociales en su familia, profesión y hábitat, ciudad, región y país en donde el Estado sea el garante de los derechos y las obligaciones hacia una sociedad de tipo pluralista.

Con este nuevo entendimiento del ser humano desde lo social y lo colectivo, la ciudad y el barrio se presentan como los escenarios por excelencia de esa nueva definición de los hombres y las mujeres. Esta situación introduce la necesidad de abordar a fondo la discusión política sobre la existencia o no de la ciudadanía en las urbes, "[...] la ciudad sin ciudadanía es un imposible político. La de las urbes sin derechos 
efectivos es una nefasta creación de nuestras clases dirigentes derivada de su incapacidad de crear instituciones democráticas" (Giraldo Isaza, 2001: 12).

Una ciudad sin ciudadanía es lo que Ingersoll (1996: 14) ha denominado el "espejismo de ciudad", una realidad urbana que se constituye en un mercado de experiencias simbólicas. El espejismo de la ciudad proyecta el deseo de pertenecer a la sociedad sin tener que llevar a cabo sus rituales de compromiso. El espejismo de ciudad muestra una ciudad sin vida urbana real, en la cual se venden experiencias de tipo simbólicas, como una mercancía que se compra y que no genera sentido de pertenencia, ni comunidad ciudadana, ni participación pública o política.

Para los intereses predominantes que tienen lugar en la ciudad contemporánea, el habitante ideal de la ciudad no es propiamente el pleno ciudadano, una persona que exige la prestación de servicios por parte de las autoridades y que se siente responsable del ambiente local, sino el turista, el sujeto ajeno, no atado, no perteneciente, alguien que consume y que no siente derecho a intervenir ni pública ni políticamente (Ingersoll, 1996: 16) ${ }^{10}$.

Las urbes sin personas, sin ciudadanos, resultan sintomáticas no sólo de la desconfianza de las ciudades típicamente modernas, sino también del cambio de época generalizado en la conciencia urbana, que ahora ve la movilidad (y las demás funciones urbanas) por encima de la comunidad. El espejismo de la ciudad coincide con lo que en palabras de Höffe (2004: 96) corresponde a la ausencia de sentido comunitario en los procesos democráticos y ciudadanos en los que se sustenta la dimensión política de la ciudad, una ausencia caracterizada por: (a) la falta del interés de velar por el interés común; (b) la apatía por detentar cargos públicos; (c) la falta de un compromiso y responsabilidad social; y (d) la ausencia de todo compromiso por el futuro colectivo y por trasmitir la cultura.

Solo mediante el ataque a dichos síntomas por medio de las políticas de ciudad y la presencia de dicho sentido comunitario es que se genera efecto colateral interesante que integra la última implicación del entendimiento político de la ciudad, esto es, la vinculación personal de los ciudadanos y el fortalecimiento del tejido social, el aumento del sentido de pertenencia que fomenta la participación ciudadana en todas sus manifestaciones (Höffe, 2004: 97) hacia ello deben dirigirse las prácticas de gobierno, las políticas de ciudad y la acción ciudadana.

\section{Palabras finales}

Planificar la ciudad por medio de políticas de ciudad que tengan como norte el derecho a ella integra un reto enorme que exige replantear la lógica desde la cual se actúa. Se trata de ir más allá de las temáticas que se abordan en las políticas sectoriales, se trata de ir más allá del abordaje territorial de la ciudad en las políticas urbanas.

Se trata de entender la ciudad como una creación humana compleja, como un reto político y ciudadano y dar respuesta, desde el quehacer lo público y lo privado, por medio de políticas de ciudad, a dicha situación. Para ello, como se planteara en este artículo, se requiere entender que la ciudad implica una lucha por el poder y que las políticas sobre esta deben permitir que este se ejerza de manera ciudadana y a favor de la ciudadanía. Se requiere que las políticas de ciudad, desde su formulación hasta su evaluación, fomenten y fortalezcan la comunidad ciudadana; al igual que desarrollar prácticas democráticas directas; fomentar la participación ciudadana; y el pleno ejercicio de la ciudadanía.

Las políticas de ciudad no se materializan únicamente como policy desde la acción pública, sino que implican una serie de vínculos con la política como juego del poder (politics), cómo este juego impacta la acción y cómo esa misma acción pública da cuenta de ese juego diverso y complejo. Se trata finalmente de entender que las políticas de ciudad se refieren a todos los temas, aspectos, necesidades y sectores de la ciudad, más o menos territoriales, pero en todo caso deben responder a una idea de ciudad, a una ciudad que implica un reto política, ciudadano, ético y humano, las políticas de ciudad implican una forma distinta de concebir su gobierno, gestión y acción ciudadana. 


\section{Notas}

${ }^{1}$ El presente texto es resultado del proyecto de investigación denominado: "Planeación participativa para la garantía del derecho a la ciudad: Análisis del proceso de formulación, discusión y elaboración del Plan Centro de Bogotá (Colombia)" desarrollado entre 2009 y 2011. Agradezco profundamente el apoyo constante de Beatriz García Moreno, Ana Milena Montoya Ruiz y Milton Andrés Rojas Betancur, quienes siempre estuvieron dispuestos/as a leer y comentar mis avances. De igual manera a Juana Martínez Quintero, cuyo apoyo editorial hizo posible esta versión.

${ }^{2}$ La discusión sobre las políticas públicas es amplia y profunda, para los efectos de la presente investigación se entienden en el marco de los postulados de: (MULLER, 2009).

${ }^{3}$ Se conoce y acepta que el modelo de democracia griega no incluía a todos los habitantes de la ciudad-estado y que en detalle permitía la posibilidad de encuentro solamente de algunas personas, de unos pocos, en desmedro de muchos otros. Sin embargo para los efectos de los planteamientos teóricos que se desarrollan es la actitud de encuentro, de lo colectivo, de lo público, lo que se resalta como valioso de dicha configuración democrática, cuyos vacíos vendrían a ser llenados por la humanidad con la creación del estado moderno, las revoluciones liberales y sociales de los últimos tres siglos.

${ }^{4}$ El concepto de espacio "público-público" se recupera de diferentes aportes de Fernando Viviescas y Fabio Giraldo y en términos generales hace referencia a los encuentros y convivencias humanas que el espacio público físico permite o debe permitir.

${ }^{5}$ Dicha idea nostálgica hace referencia, términos generales, a una sociedad pequeña, culta, homogénea, interesada por sus asuntos, donde la política juega un rol determinante y, además, existen actitudes ampliamente deliberativas.

${ }^{6}$ Hace referencia a la política entendida como "Politics", como juego político en las palabras de (Muller, 2009).

${ }^{7}$ Hace referencia a política como “Policy”, como acción pública en palabras de (Muller, 2009).

${ }^{8}$ Cfr. Gemeinschaft.

${ }^{9}$ Cfr. Gesellschaft.

${ }^{10}$ Ingersoll se refiere a las ideas de: (Vattimo, 1994).

\section{Bibliografía}

Amendola, Giandomenico (2000), La ciudad posmoderna: magia y miedo de la metrópolis contemporánea. Celeste Ediciones, Madrid.

Bauman, Zygmunt (2010), Modernidad Líquida. Fondo de Cultura Económico, Buenos Aires.

Berman, Marshall (1989), Todo lo sólido se desvanece en el aire: la experiencia de la modernidad. Siglo XXI, México.

Borja, Jordi (2005), La ciudad conquistada. Alianza Editorial, Madrid.

Cortina, Adela (1998), Ciudadanos del mundo: hacia una teoría de la ciudadanía. Alianza Editorial, Madrid.

Fernandes, Edésio (2006a), "The City Statute in Brazil". En: UNESCO. (2006). International Public debates. Urban Policies and the Right to the City. UNESCO, Paris.

Ídem (2006b), "Updating the Declaration of the Rights of Citizens in Latin America: Constructing the Right to the City in Brazil". En: UNESCO. (2006). International Public debates. Urban Policies and the Right to the City. UNESCO, Paris.

Ídem (2007), "Constructing the "Right to the City" in Brazil”. En: Social \& Legal Studies, 2007; 16; 201. pp 201 219.

García Moreno, Beatriz (1996), "Búsqueda de la poética de la ciudad: la ciudad como obra de arte en permanente construcción”. En: Giraldo ISAZA, Fabio y Viviescas, Fernando (1996), Pensar la Ciudad. Tercer Mundo Editores, Bogotá.

Ídem (2003), “Ciudad, Instituciones y Deseos”. En: Revista Trans, No. 3, Abril 2003. pp 189 - 198. 
García Vázquez, Carlos (2004), Ciudad Hojaldre. Visiones urbanas del siglo XXI. Gustavo Gili, Barcelona.

Giraldo Isaza, Fabio y Viviescas, Fernando (1996), Pensar la Ciudad. Tercer Mundo Editores, Bogotá.

Giraldo Isaza, Fabio (1998), Ciudad y Crisis: hacia un nuevo paradigma? Cenac, Bogotá.

Ídem (2001), "Prólogo". En Alfonso Roa, Oscar A. (2001), Ciudad y Región en Colombia. Nueve Ensayos de Análisis Socioeconómico y Espacial. Universidad Externado de Colombia, Bogotá.

Ídem (2002), "Ciudad y creación”. En: Torres Tovar, Carlos Alberto, Viviescas Monsalve, Fernando y Pérez Hernández, Edmundo (2002), La Ciudad: hábitat de diversidad y complejidad. Universidad Nacional de Colombia, Bogotá.

Giraldo Isaza, Fabio y López, Héctor Fernando (2002), "La metamorfosis de la modernidad”. En: Viviescas Monsalve, Fernando y Giraldo Isaza, Fabio (2002), Colombia: el despertar de la modernidad. Foro Nacional por Colombia, Bogotá.

Gorz, André (2002), "La utopía contra la modernidad”. En: Viviescas Monsalve, Fernando y Giraldo Isaza, Fabio (2002), Colombia: el despertar de la modernidad. Foro Nacional por Colombia, Bogotá.

Höffe, Otfried (2004), Ciudadano económico, ciudadano del Estado, ciudadano del mundo. Ética en la era de la globalización. Katz Editores, Buenos Aires.

Ingersoll, Richard (1996), “Tres tesis sobre la ciudad”. En: Revista de Occidente, No. 185. p 11-44.

Lash, Scott (1997), Sociología del Posmodernismo. Amorrortu, Buenos Aires.

Le Corbusier (1973), Principios de Urbanismo. La Carta de Atenas. Editorial Ariel, Barcelona.

Lefevre, Henri (1991), The production of the space. Basil Blackwell, Oxford.

Lindón, Alicia (2007), La ciudad y la vida urbana a través de los imaginarios urbanos. En: EURE, agosto, año XXXIII, número 99, pp 7-16. Pontificia Universidad Católica de Chile, Santiago de Chile.

Lyotard, Jean Francois (2004), La condición posmoderna: informe sobre el saber. Cátedra, Madrid.

Malaver, José Antonio (1996), "La ciudad son los hombres, los hombres son la ciudad”. En: GIRALDO ISAZA, Fabio y VIVIESCAS, Fernando. (1996). Pensar la Ciudad. Tercer Mundo Editores, Bogotá.

Park, Robert E. (1967), “The city: suggestion for the human behavior in the urban environment”. En: Park, Robert E., Burgess, Ernest W. and McKenzie, Roderick D. (1967), The City. University of Chicago Press, Chicago.

Rossi, Aldo (1986), La Arquitectura de la Ciudad. Gustavo Gili, Barcelona.

Tonkiss, Fran (2005), Space, the city and social theory. Polity Press, Cambridge.

Tönnies, Ferdinand (2002), Community and Society. Dover Publications, Mineola.

Vattimo, Gianni (2002) "Posmodernidad: ¿una sociedad transparente?”. En: Viviescas Monsalve, Fernando y Giraldo Isaza, Fabio (2002), Colombia: el despertar de la modernidad. Foro Nacional por Colombia, Bogotá.

Velásquez Carrillo, Fabio (2004), "Pensar la ciudad en perspectiva de derechos". En: Velásquez Carrillo, Fabio (2004), Ciudad e Inclusión: por el Derecho a la Ciudad. Foro Nacional por Colombia, Bogotá.

Viviescas Monsalve, Fernando, Fernando y Giraldo Isaza, Fabio (2002), Colombia: el despertar de la modernidad. Foro Nacional por Colombia, Bogotá.

Viviescas Monsalve, Fernando, Fernando (2002), "Pensar la ciudad colombiana: el reto del siglo XXI”. En: Torres Tovar, Carlos Alberto, Viviescas Monsalve, Fernando y Pérez Hernández, Edmundo (2002), La Ciudad: hábitat de diversidad y complejidad. Universidad Nacional de Colombia, Bogotá. 
Recibido: 11.01.2012

Aceptado: 11.03.2012 